\title{
OPTIMAL MAINTENANCE PLANNING FOR BRIDGE STRUCTURES CONSIDERING EARTHQUAKE EFFECTS
}

\author{
Hitoshi Furuta \\ Kansai University, Informatics, Japan \\ furuta@res.kutc.kansai-u.ac.jp
}

Kazuhiro Koyama

Kansai University, Japan

kotaro-@sc.kutc.kansai-u.ac.jp

\begin{abstract}
In the design of bridge structures, it is evident that the most important is to acquire their safety. However, there is a limitation to increase the safety because of the financial constraint. Especially, the reduction of construction cost is quite desirable under the severe economic condition in Japan.

Recently, Life-Cycle Cost (LCC) analysis has been paid attention as a possible and promising concept to achieve a rational maintenance program. In this study, a stochastic model of structural response is proposed, which accounts for the variation due to the uncertain characteristics of earthquakes, and the probability of failure is calculated based on the reliability theory. Using the failure probability, LCC can be calculated for the bridge structure with earthquake excitations.
\end{abstract}

Keywords: Bridge Structure, Failure Probability, Life-Cycle Cost, Reliability Theory, Seismic Analysis

\section{Introduction}

Many existing bridges in Japan are suffering from damage due to the deterioration of materials, heavy traffics and aging. In the future, it is evident that serious social problems will arise as the number of damaged bridges increases. Considering the present social and economic situation of Japan, it is urgent and important to establish an optimal maintenance strategy for such existing bridges so as to ensure their safety in satisfactory levels. Life-Cycle Cost (LCC) has been paid attention as a possible 


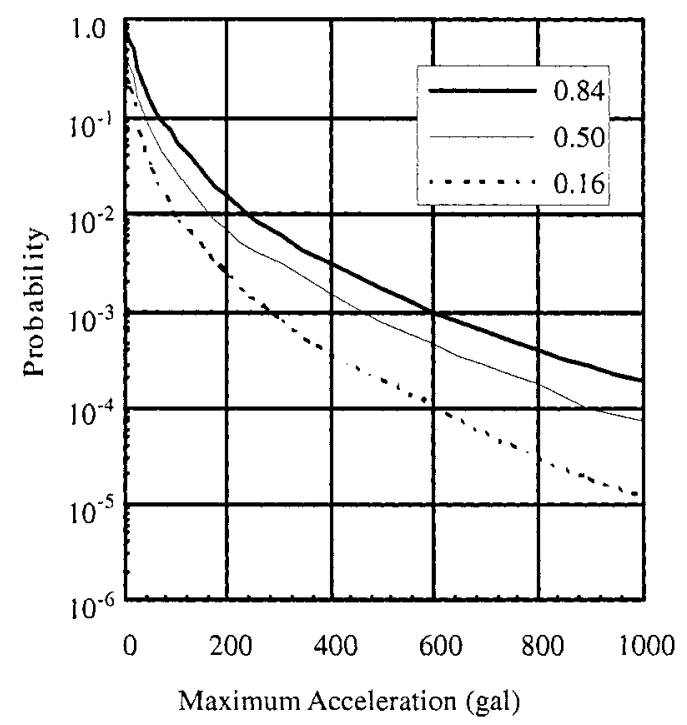

Figure 1. Seismic Hazard Curve

and promising method to achieve a rational maintenance program. Generally, LCC consists of initial cost, maintenance cost, and renewal cost. However, when considering Life-Cycle Cost in the region that frequent earthquakes occur, it is important to take into account the social and economical effects due to the collapse of structures as well as the minimization of maintenance cost. The loss by the collapse of structures due to the earthquakes can be defined in terms of an expected cost and introduced into the calculation of LCC. In this study, a stochastic model of structural response is proposed, which accounts for the variation due to the uncertain characteristics of earthquakes, and the probability of failure is calculated based on the reliability theory.

\section{Earthquake Occurrence Probability in Service Time}

In this study, the earthquake occurrence probability is evaluated by using seismic hazard curve. In the hazard curve, the annual exceedance probability of earthquake is calculated by considering the distribution of distance from epicenter, historical earthquake records, horizontal maximum acceleration and active fault. The hazard curve used here is shown in Figure 1. 


\section{Analysis of Required Yield Strength Spectrum}

In this study, a probability model of yield strength is developed by using the yield strength spectrum. The yield strength spectrum shows a nonlinear relation between natural period and yield strength. This spectrum can be obtained for various ductility factors and damage indices. For natural period, target ductility factor, earthquake level, type of soil and number of seismic wave, the values presented in Table 1 are used.

\begin{tabular}{|c|c|}
\hline Natural Period T & $0.1^{\prime} 5.0(\mathrm{sec})$ \\
\hline Target Ductility Factor $\mu_{T}$ & $1.0,2.0$ \\
\hline Earthquake Level & $400,800(\mathrm{gal})$ \\
\hline Type of Soil & $1,2,3$ \\
\hline Seismic Wave & 18 \\
\hline
\end{tabular}

Table 1. Analysis Condition

Figure 2 shows the calculated results of the yield strength spectrum. Because there are many data, only representative values are shown in Figure 2,3. Figure 3 shows the analysis results using the data presented in Figure 2. There results are obtained through the regression analysis for the earthquake level of $800 \mathrm{gal}$. In this study, the distribution of yield strength is obtained by using this spectrum.
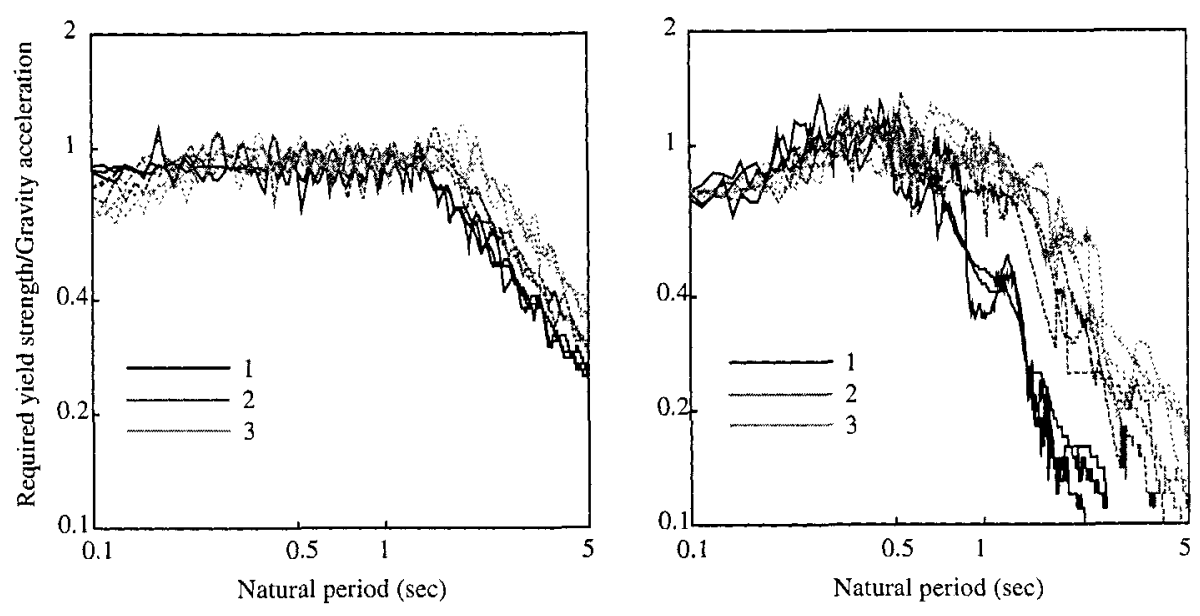

Figure 2. Required Yield Strength Spectra 


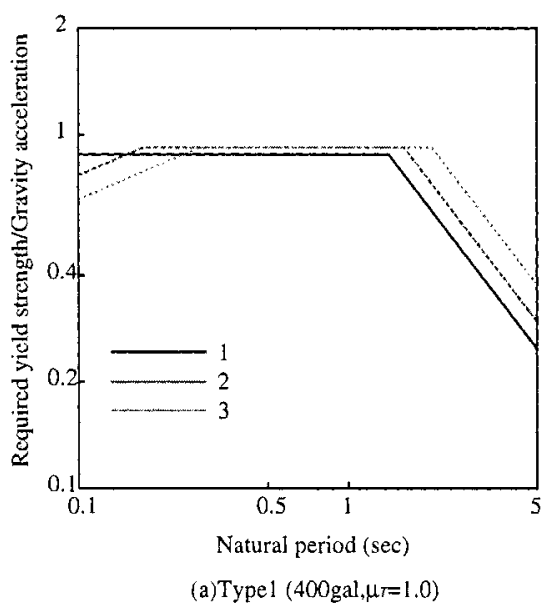

(a)Typel $\left(400 \mathrm{gal}, \mu_{T}=1.0\right)$

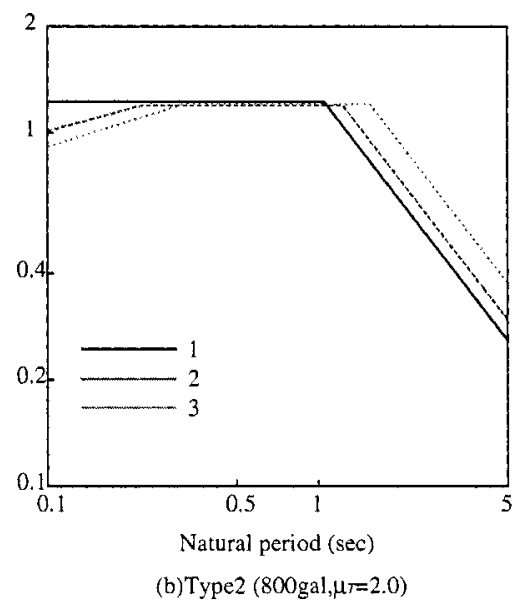

(b) Type2 (800gal, $\mu=2.0)$

Figure 3. Standard Required Yield Strength Spectra

\subsection{Probability Model of Required Yield Strength}

When designing a structure, type of soil, ground maximum acceleration and target ductility factor should be given. The natural period of the structure is changed by the design. In order to make the design simple, it is not good that the probability model of the required yield strength changes depending on the design. In this study, a probability distribution model of yield strength is developed for various types of soil and target ductility factors. In this model the required yield strength can be constant regardless of the natural period. Here, the probability distribution model is assumed to be the lognormal distribution. The probability density function of the lognormal distribution is given in Figure 1

$$
f_{P_{n y}}(x)=\frac{1}{\sigma_{\ln (x)} \sqrt{2 \pi}} \frac{1}{x}\left[-\frac{1}{2}\left(\frac{\ln (x)-\mu_{\ln (x)}}{\sigma_{\ln (x)}}\right)^{2}\right]
$$

$\mu_{\ln (x)}$ is the standard value of required yield strength, $\sigma_{\ln (x)}$ is standard deviation of every response ductility factor. In other words, if to understand a standard value of the probability function, the probability model of required yield strength can be calculated. We calculated a standard deviation about the type of soil and target ductility factor. (Refer to Table 2.) 


\begin{tabular}{|c|c|c|c|c|}
\hline Ductility Factor & Earthquake & Soil & $\operatorname{Var}_{l n}$ & $\sigma_{l n}$ \\
\hline \multirow{6}{*}{1} & \multirow{3}{*}{1} & 1 & 0.0030 & 0.0551 \\
\hline & & 2 & 0.0029 & 0.0537 \\
\hline & & 3 & 0.0052 & 0.0722 \\
\hline & \multirow{3}{*}{2} & 1 & 0.0049 & 0.0699 \\
\hline & & 2 & 0.0054 & 0.0736 \\
\hline & & 3 & 0.0044 & 0.0662 \\
\hline \multirow{6}{*}{2} & \multirow{3}{*}{1} & 1 & 0.0222 & 0.1488 \\
\hline & & 2 & 0.0343 & 0.1852 \\
\hline & & 3 & 0.0287 & 0.1684 \\
\hline & \multirow{3}{*}{2} & 1 & 0.0306 & 0.1749 \\
\hline & & 2 & 0.0361 & 0.1900 \\
\hline & & 3 & 0.0410 & 0.2025 \\
\hline
\end{tabular}

Table 2. Result of Analysis

\section{Reliability Analysis of Steel Bridge Pier}

As an example, a steel bridge pier is employed, in which its failure probability and reliability index are calculated.

\subsection{Analysis Model}

As mentioned previously, a steel bridge pier is used for the analysis model. Figure 4 shows the detail of the steel bridge pier and its cross section. To simplify the design, it is assumed that the cross section is square without stiffening and the width of flange and web is equal. To avoid the local buckling, this pier is designed according to the gJapanese Specification of Highway Bridgeh. Then, the minimum thickness is determined so as to satisfy the following requirement: where the steel material is SM490Y.

In this study, the residual stress and the initial deflection are considered for the initial imperfection of the steel pier. This pier is used for a three-spanned continuous steel girder bridge with $40 \mathrm{~m}$ span length. The bridge has two main girders and Reinforced Concrete (RC) slabs. For the design condition, the vertical load $\mathrm{P}$ is calculated to be 10.84 $\mathrm{MN}$, which corresponds to the reaction force to the superstructure. The height of the steel pier is $10 \mathrm{~m}$, and its width is $2,000 \mathrm{~mm}$ and its thickness is 42 to $60 \mathrm{~mm}$.

$$
\frac{b_{f}}{t_{f}}=\frac{b_{w}}{t_{w}} \leq 48
$$



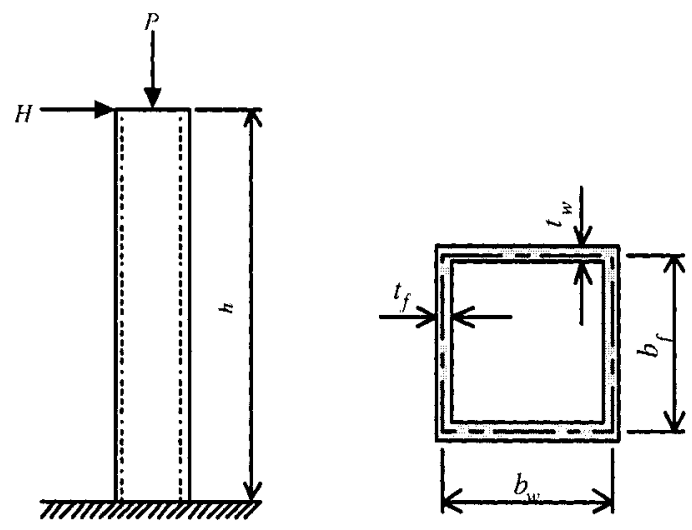

Figure 4. Analysis Model

\subsection{Limit State Functions}

In this study, both the serviceability limit condition and the ultimate limit condition are taken into account as the limit state.

Serviceability Limit Condition. The elastic limit of the structure is employed for the serviceability limit condition. The limit state function is given as follows:

$$
Z=P_{a}-P_{y n}
$$

where $P_{a}$ means the yield strength of the structure and $P_{y n}$ means the required yield strength of ductility factor $\mu=1.0$.

Ultimate Limit Condition. In this study, the ductility factor $\mu$ is taken as the parameter which decides the ultimate limit condition. Considering the difference of structural type and structural material, the reliability analysis is performed for the ductility factor $\mu=1.0,2.0$, $3.0,4.0,5.0$. Then, the limit state function is given as

$$
Z=P_{a}-P_{y n}
$$

where $P_{y n}$ is required yield strength of the ductility factor $\mu=1.0,2.0$, $3.0,4.0,5.0$.

\subsection{Reliability Analysis Model}

For the above ultimate and serviceability limit functions, the reliability analysis is performed, where the load combination is not considered. 
Because the distribution of earthquake force becomes a non-normal distribution, the safety margin $Z$ also becomes a non-normal distribution. Therefore, it is necessary to transfer $\mathrm{Z}$ to a normal distribution.

$$
\begin{gathered}
F_{c}\left(Z^{*}\right)=\Phi\left(\frac{z^{*}-\mu_{c}}{\sigma_{c}}\right) \\
f_{c}\left(z^{*}\right)=\frac{1}{\sigma_{c}} \varphi\left(\frac{z^{*}-\mu_{c}}{\sigma_{c}}\right)
\end{gathered}
$$

where $\mu_{c}$ and $\sigma_{c}$ are the mean value and the standard deviation of the normal distribution which is used for the approximation. The two values are unknown variables and to be obtained by solving the above equations. Then the reliability index is calculated as

$$
\beta=\frac{\mu_{c}}{\sigma_{c}}
$$
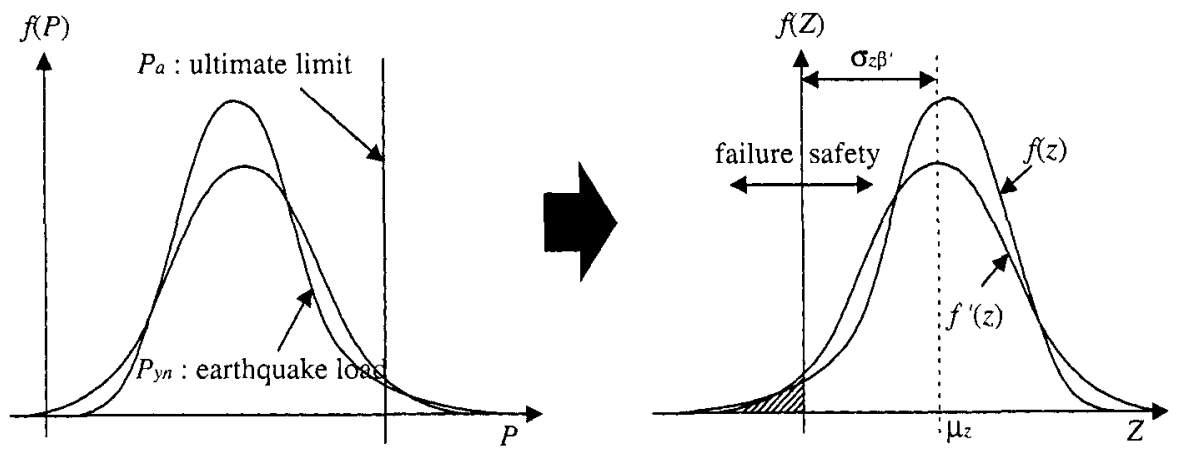

Figure 5. Reliability Index

\subsection{Reliability Analysis of Steel Bridge Pier}

Since it needs enormous task to analyze all the target ductility factor and type of soil, only types II soil is taken into consideration and the corresponding damage index to the earthquake is assumed as follow:

For type I earthquake, 400 gal is employed as the maximum acceleration. Type I earthquake is defined in the Japanese Specification of Highway Bridge. This type I earthquake is used to check the seismic design for middle earthquakes. Then, the damage index of the structure is assumed to be $\mu_{T}=1.0$. On the contrary, Type II earthquake is used to check for strong earthquakes, in which the maximum acceleration is 800 gal. Then, the damage index of the structure is $\mu_{T}=2.0$. 


\begin{tabular}{|c|c|c|}
\hline Item & Unit & Cost(Yen) \\
\hline Material Cost & $t$ & 97,585 \\
\hline Painting Cost & $m^{2}$ & 1,700 \\
\hline Transport Cost & $t$ & 9,000 \\
\hline
\end{tabular}

Table 3. Initial Cost

\section{Life-Cycle Cost Considering Earthquake Effects}

Here, initial cost and loss of the steel bridge pier are described. Based on the result obtained previously, LCC is formulated and calculated for the steel bridge pier.

\subsection{Initial Cost and Loss Cost}

As the initial cost, only pier is considered, because the sufficient data for the whole bridge is not prepared. Then, the initial cost consists of material cost, painting cost and transportation cost. (Table 3) It is also assumed that type I earthquake will lose $80 \%$ of the initial cost and type II earthquake will lose $110 \%$.

\subsection{Formulation of LCC Considering Earthquake Effects}

The failure probability of structure is calculated by (8).

$$
P_{f, t=L}=P(t) \times P_{f}
$$

Then, LCC is formulated as (9), where $i$ is the social discount rate and assumed to be $2 \%$.

$$
L C C=C_{I}+P_{f, t=L} \frac{C_{F}}{(1+i)^{T}}
$$

\subsection{Result of Analysis}

The relation between LCC and failure probability is shown in Figure 6 , in which LCC is calculated with the same assumption as those used in the reliability analysis.

We calculated LCC about the order which was equal to the reliability analysis. 
Case 1. For the case shown in Figure 6, LCC is minimized when the thickness $t_{f}=t_{w}$ is $50(\mathrm{~mm})$. Then, the failure probability $P_{f}$ is 0.03 and the reliability index $\beta$ is 1.86 .

Case 2. For the case shown in Figure 7, LCC is minimized. When the thickness $t_{f}=t_{w}$ is $56(\mathrm{~mm})$, in which $P_{f}$ is 0.12 and reliability index is 1.17 .

From these results, it is confirmed that it is possible to propose the optimal design plan in service time including the loss cost, which has the minimum LCC from the standpoint of reliability-based design, by introducing the loss of the structure due to the earthquake and the repairing cost.

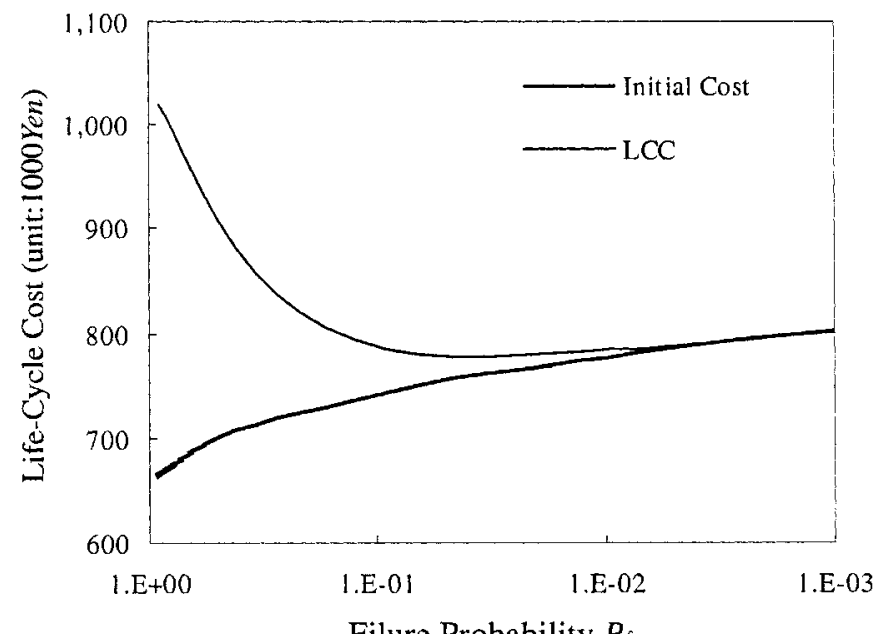

Filure Probability $P_{f}$

Figure 6. Type I eathquake, $\mu_{T}=1.0$

\section{Conclusion}

In this study, an attempt was made to propose a calculation method of LCC considering earthquake effects based on reliability index.

Through several numerical calculations, the following conclusions were derived:

1 The proposed method can calculate LCC and failure probability for the structure which shows simple behavior by the earthquake. 


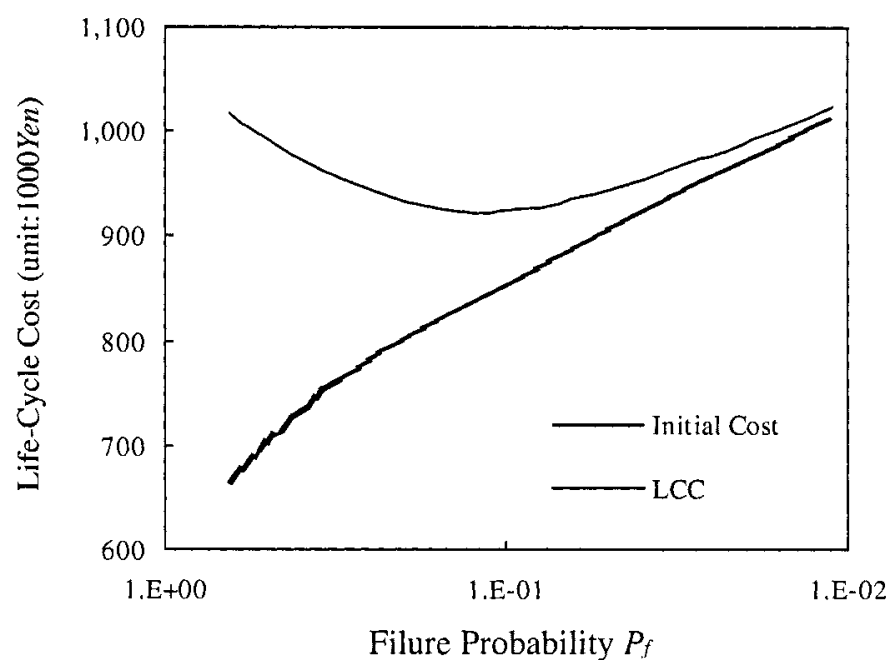

Figure 7. Type II eathquake, $\mu_{T}=2.0$

2 Considering the collapse of the structure, LCC could be evaluated by failure probability.

3 Using the reliability-based design concept, it is possible to provide a design plan to make the reliability index maximum and LCC minimum.

4 In the calculation of LCC, many factors are interrelated and include various uncertainties.

Therefore, there still remain many issues to overcome in the future. For instance, in this study, the probability model of the maximum acceleration and required yield strength was calculated by the historical earthquake records and the standard input earthquake wave of "Japanese Specification of Highway Bridge". However, when comparing the return period of the earthquake, the period of the earthquake records was too short and the available data is insufficient to estimate the earthquake intensity and the seismography. Moreover, the data of initial cost and maintenance cost were insufficient to calculate LCC of the whole bridge with accuracy. In the calculation of LCC, user cost should be accounted for as well as the earthquake occurrence and the maintenance by the deterioration of the structure. 